specially made, the bright sunshine amounted to 1634 hours; the morning is usually bright until about eleven o'clock, then clouds come up and continue until about four o'clock; by six o'clock the sky is generally cloudless. Except during the northeast monsoon, a night which is wholly cloudy is almost unknown. Under these highly advantageous conditions, there is every prospect that the establishment of this observatory will result in a great gain to astronomy, especially in the department of solar physics.

Star Catalogues.--An admirable részimé of the history of star cataloguing, from the pen of Mdlle. Klumpke, the gifted directress of the Bureau des Mesures of the Paris Observatory, appears in the current number of the Bulletin of the Astronomical Society of France. From an instrumental point of view three great epochs may be recognised, each marked by some im portant discovery. The first epoch is that in which the line of vision is defined by hollow cylinders or by an alidade, and extends from the time of Hipparchus to that of Hevelius; it comprises the catalogues of Hipparchus, Ptolemy, Ulugh-Beigh, and Tycho Brahe. The catalogue of Hevelius, though drawn up from observations with the naked eye, marks a transition period, as he took advantage of the application of the pendulum to the regulation of clocks.

The second epoch is marked by the application of the telescope for accurate sighting of the heavenly bodies, and the employment of the sidereal clock. This period commenced with Flamsteed, and extends even to the present time. In the thirc epoch the photographic plate replaces the eye. Enthusiasm for this method of cataloguing the stars commenced with the fine results obtained by the Henrys, but it should not be forgotten that as far back as I865, Rutherford obtained photographs of stars down to the ninth magnitude, and that he clearly foresaw the advantages to be derived from the photographic method All the world knows now that a great photographic chart of the heavens, initiated by the late Admiral Mouchez, is in course of construction, eighteen observatories participating in the gigantic undertaking. Mdlle. Klumpke estimates that this international catalogue will contain upwards of three millions of stars.

The photographic method, however, does not yet appear to be without imperfections, as the impressions on the negatives are not certainly permanent. In a communication to the editor of the Observatory, Dr. Isaac Roberts gives some figures relating to the disappearance of the smaller images in the course of years; in one negative no less than I 30 out of 364 star images had disappeared in nine and a quarter years. Hence it is important that as short a time as possible should elapse between the taking of a photograph and its reduction, or, better still, its manifolding by some carbon process.

\section{THE PLACE OF ARGON AMONG THE} ELEMENTS

THE position of argon in a classification of the elements 1 depending on atomic weights has been recently defined by C. J. Reed (Journal of the Franklin Institute, July). The elements are assigned positions on a plane determined by ats sissa proportional to their atomic weights and ordinates proportional to their ralency. Oxygen is assumed to have an electronegative valency 2 , and the valency of other elements is referred to this as standard; electro-positive valency is measured upwards, electro-negative downwards from the zeroaxis. Under these conditions most of the elements fall on a peculiar series of double, equi-distant, parallel straight lines, connecting elements in order of their atomic weights and separated alternately by distances corresponding to one and sixteen units of atomic weight respectively.

If the plane be now folded into a cylinder with axis parallel to the abscissæe and a circumference of eight units of valency, it is found that the upper and lower parts of the connecting lines coincide; the whole of these lines then form a parallel pair of spirals on the surface of the cylinder, and valency in angular measure becomes directly proportional to atomic weight.

The regularity with which the elements of lower atomic weight fall alternately on each of the parallel spirals is very striking, but this regularity is not maintained among elements of high atomic weight, notable deviations occurring with most of the elements of which the atomic weight ranges from 100 to 130 . The axis of atomic weights represents the valency +0 or +8 and is cut by the double spiral in fifteen points. There should then be a group of fifteen elements having a valency of zero or eight, and their atomic weights should be, respectively, 4, 20, 36, 52, 68, 84 , I00, I16, I32, 148, 164, I80, 196, 212 , and 228 . All the known elements appear to be grouped together on certain regions of the surface of the cylinder, other parts remaining comparatively bare. The only members of this family to be expected to occur in terrestrial matter will be those in the inhabited regions of the cylinder surface. The hypothetical elements having atomic weights $20,36,84$, and 132 are the most necessary from this point of view.

It seems reasonable to suppose from the peculiar position of these elements on the border-line between electro-negative and electro-positive valencies, that they should be more strongly electro-negative than the corresponding members of the sulphur group, and should nevertheless be without valency (or octads). They should, in general, be more volatile than the corresponding members of the sulphur group. As electro-negative valency diminishes in any group with increase of atomic weight, the element 196, if it exists, cannot be expected to be electronegative. This element should be a volatile metal, heavier and scarcer than gold, and capable of easier reduction to the metallic state; it should be capable of forming an oxide $\mathrm{RO}_{4}$ or a salt $\mathrm{K}_{2} \mathrm{RO}_{5}$. The volatile metal osmium agrees with the requirements of this element very closely. Similarly, ruthenium may possibly be the element Ioo.

Finally, argon falls naturally into the place of element 20 , and possesses, so far as is known, the properties to be expected of this element in position 20 in the new group. Argon and element 36 should be comparatively abundant in nature, while 84 and 132 should be scarce, but not more rare than selenium and tellurium.

On Mr. Reed's system, argon should be element 36 if it be monatomic as now believed, and not 20 as he assumes; the actual atomic weight found, $39^{\circ} 9$, would then indicate the possibility of the presence in argon of some small quantity of element 84 or element 132 . It is remarkable also that, if helium has the atomic weight 4 , it falls naturally in this group, and that its atomic weight deduced from the observed density is somewhat greater than this number. If this difference should be due to the presence of some small quantity of element 84 , then the spectroscopic evidence leading to the conclusion that argon and helium contain a common constituent would be explained.

\section{POCKET GOPHERS OF THE LNITED $S T A T E S$.}

IN Bulletin No. 5 of the U.S. Department of Agriculture, Mr. Vernon Bailey gives an account of the habits and lifehistory of the Pocket Gophers of the United States, which contains a number of interesting facts and observations derived from various sources. These curious little rodents live underground in burrows which they tunnel in the soil. When working their way through the earth, they use the upper incisors as a pick to loosen the ground, while the fore-feet are armed with strong curved claws for digging. When a sufficient quantity of soil has accumulated behind an animal, he turns in the burrow and pushes it out in front until an opening in the tunnel is reached; the earth is here discharged, and forms a hillock similar to the hills thrown up by moles. Gopher burrows are extended and added to year by year, and the course is marked by the hills of soil brought up to the surface. Gophers do not hibernate, as has been commonly supposed, but work steadily throughout the winter. They do a great deal of good in mixing the soil, and in this way are probably most useful on poor or uncultivated ground. But, on the other hand, in agricultural districts the animals are highly injurious; they devour potatoes and other tubers and roots in large quantities, as well as corn, wheat, and other farm crops ; and they destroy great numbers of fruit trees by gnawing off the roots. Gopher burrows also often do a great deal of damage in meadows or on the banks of artificial water-courses. So great is the harm done by Gophers, that in many districts bounties have been offered for their capture. One of the most striking features of Pocket Gophers is their possession of cheek pouches opening outside the mouth. It is commonly supposed that these pouches are used for carrying earth out of the burrows; but Mr. Bailey's investigations lead him unhesitatingly to the conclusion that this view is erroneous; they are used only for carrying food--pieces of

NO. I 342, VOL. 52 ] 
potato and roots, leaves, \&c.-to be eaten at ease in the seclusion of the animals' burrows, or to be stored up for use in the winter. The food is passed into the pouches by the forefeet; and the animals empty their pockets by pressing the sides of the head with the fore-feet from behind forwards, so that the contents fall out in front of them. In disposition Gophers are very fierce; and on the rare occasions on which they wander from their holes, frequently attack passers-by without any provocation. They are not very prolific animals, as is commonly stated, for only one litter of two or three young is produced in a year; but, although their rate of increase is slow, their mode of life protects them from many enemies which attack squirrels, mice, and many other rodents. The Pocket Gophers of the United States belong to three genera, Geomys, Cratogeomys, and Thomomys; Mr. Bailey gives two charts illustrating the distribution of these different genera and their constituent species.

\section{COLOUR PHOTOGRAPHY.}

A $\mathrm{N}$ important paper on the theory of colour photography is A contributed to No. 6 of Wiedemann's Annalen, by Herr Otto Wiener. The paper deals with the methods of attacking this problem which are based, not upon the photography of the different constituents of coloured light and their subsequent recognition-like Mr. Ives's heliochromy and similar processes - -but upon the direct production of colour by the influence of light upon certain chemical substances. The most recent, and in a way the most successful of these methods is that due to Lippmann, and the question raised by Herr Wiener is whether the old processes invented by Becquerel, Seebeck, and Poitevin are based upon interference colours like Lippmann's, or upon "body colours," z.e. colours produced by partial absorption of the incident light. That Lippmann's colours are due to interference may be very simply proved by breathing upon a plate with a photograph of the spectrum, when the colours quickly wander towards the violet end, this result being due to an in crease in the distance between the nodal layers. This experiment cannot be applied to a spectrum photographed by Becquerel's method. But Herr Wiener succeeded, by a simple and ingenious contrivance, altering the path of the rays through the coloured film by placing a rectangular prism on the plate, with its hypothenuse surface in contact with the spectrum. This experiment had the startling result that that part of the spectrum covered by the prism appeared strongly displaced towards the red. Hence Zenker's theory of Becquerel's process, enunciated in I868, which ascribed the colours to interference, is substantiated. Instead of Becquerel's homogeneous sheet of silver chloride containing subchloride, Seebeck used the powder, and Poitevin mounted the salt on paper. In these two processes the effect described is not observed. Hence these colours are body colours in these two cases. The production of these body colours is a very mysterious process, but the author hopes that here will eventually be found a satisfactory solution of the problem. To account for the production of these colours he advances a remarkable theory which has a well-known analogy in comparative physiology. Given a collection of compounds of silver chloride and subchloride of indefinite proportions, such as those which Mr. Carey Lea calls by the collective name of "photochloride," we must suppose according to the modern kinetic theories that they are undergoing a rapid series of successive modifications. When the red combination happens to be exposed to red light, it reflects it without absorption, and will therefore no longer be aftected or changed by it. Similarly for the other cases. This is another process of "adaptation." The author describes some experiments which prove that this is the true explanation, and points out the importance of this view, not only for colour photography, but for the production of colours in the animal world.

\section{THE SLATE MINES OF MERTONETHSHIRE. ${ }^{-}$}

$\mathrm{A}^{\mathrm{N}}$ official Blue Book drawn up by a Departmental Committee A appointed by Mr. Asquith, and referring to the dangers of a brief account of the mode of occurrence, the method of getting the slate by true mining operations is described, and the principal

1 Report of the Departmental Committee upon Merionethshire Slate Mines, with Appendic s. Presented to both Houses of Parliament by command of Her Majesty, r895.

NO. I 342 , VOL. 52$]$ causes of accidents are enumerated and explained. Judging by the statistics of the last nineteen years, the underground worker in Merionethshire is exposed to greater risks than the average collier ; some 40 per cent. of the deaths are caused by falls of rock, a fact which causes no surprise when one considers the conditions under which the slate-getters carry on their daily work in huge chambers, the roofs and sides of which cannot be examined without rigging up lofty ladders.

An interesting table of death-rates shows that the Merionethshire slate quarrymen are better off as regards the safety of their occupation than many other classes of workmen, such as navvies, railway servants, and sailors.

The medical evidence, especially that of Dr. Richard Jones, is very complete, and we learn that some of the ills of the Merionethshire quarrymen are practically of their own making. Judging by the report and the evidence upon which it is based, the men are not cleanly in their ways, and if their sober habits lead them to ruin their digestions by stewed tea, it becomes a question whether their so-called, but incomplete, temperance is an unmixed benefit.

For preventing accidents, the Committee make several useful suggestions; one of the most important is their advocacy of "channelling machines" or " groove cutters," for assisting in getting the slate, instead of violently wrenching off the blocks by blasting.

The value of the report is enhanced by some useful appendices, a copious index of the evidence, and several woodcuts and plates. The plates are noteworthy as being the first instances of reproductions of photographs in a Blue Book by the half-tone process. Five of the eight photographs were taken underground by magnesium light; the two best, which represent ladders set up in underground chambers, are the work of Mr. Burrow, of Camborne, already well known by his successful pictures of Cornish mines.

The report is signed by Mr. Le Neve Foster, the Inspector of Mines of the district, Mr. J. E. Greaves, the owner of one of the largest slate mines, Mr. E. 5 P. Jones and Mr. J. I. Evans, both quarry managers of wide experience, and Mr. J. Jenkins, President of the Quarrymen's Union. The opinions of a practical Committee of this kind are entitled to consideration, and it will be interesting to note how far their suggestions are carried out, and how far they attain their object, viz. the increased safety and general well-being of the Merionethshire quarrymen.

\section{THE RELATION OF BIOLOGY TO GEO- LOGICAL INVESTIGATION,'}

\section{II}

The Relative Chronological Value of Fossil Remains.

R EJECTING the idea of special endowment held by early geologists, we must consider the relative chronological value of fossil remains with reference to the natural laws which have produced their characteristics and governed the various conditions of their origin. Much may profitably be said concerning the comparative chronological value of the different genera, families, \&c., belonging to one and the same class of any branch of either the animal or vegetable kingdom, or to different classes ; but I propose to discuss only the broader relations to one another of the more general kinds of fossil remains. These discussions will relate to the time-range of each of those general kinds, the various conditions under which they have been preserved, the various conditions of habitat of the animals and plants which they represent, the relative rate of evolutional development of the different kinds and their differences of reciprocal relation to one another.

No fact in historical geology is more conspicuous than that of the great differences in time range of the various kinds of organic forms, some of them having ranged through the whole of the time represented by the geological scale, while others, and among them some of the biologically most important kinds, ranged through only a comparatively small part of it.

A special grouping of the different kinds of fossil remains is more appropriate for these discussions than is a strictly systematic one, and I have therefore adopted the following: $(a)$ marine invertebrates, $(b)$ non-marine and land invertebrates, $(c)$ fishes, $(d)$ batrachians and reptiles, $(e)$ birds, $(f)$ mammals, and

1 By Charles A. White. Abstract of a series of eight essays published in the Report of the United States National Museum. (Continued from p. 26r. 